\title{
Mapping QTL for Fusarium Head Blight Resistance in a Tunisian-derived Durum Wheat Population
}

\author{
S.M. Pirseyedi ${ }^{1}$, A. Kumar ${ }^{1}$, F. Ghavami ${ }^{1}$, J.B. Hegstad ${ }^{1}$, M. Mergoum ${ }^{2}$, M. Mazaheri ${ }^{1}$, \\ S.F. KIANIAN ${ }^{3}$ and E.M. ELIAS ${ }^{1 *}$ \\ ${ }^{1}$ Department of Plant Sciences, North Dakota State University, Fargo, ND 58108, USA \\ ${ }^{2}$ Department of Crop\& Soil Sciences, University of Georgia, Griffin, GA 30223, USA \\ ${ }^{3}$ USDA-ARS Cereal Disease Laboratory, University of Minnesota, St. Paul, MN 55108, USA
}

(Received 20 September 2017; Accepted 4 July 2018,

Communicated by Á. Mesterházy)

Fusarium head blight (FHB) damage in durum wheat (Triticum turgidum L. var. durum Desf., turgidum) inflicted massive economic losses worldwide. Meanwhile, FHB resistant durum wheat germplasm is extremely limited. 'Tunisian 108 ' is a newly identified tetraploid wheat with FHB resistance. However, genomic regions in 'Tunisian108' that significantly associated with FHB resistance are yet unclear. Therefore, a population of 171 backcross inbred lines $\left(\mathrm{BC}_{1} \mathrm{~F}_{7}\right)$ derived from a cross between 'Tunisian108' and a susceptible durum cultivar 'Ben' was characterized. Fusarium graminearum (R010, R1267, and R1322) was point inoculated (greenhouse) or spawn inoculated (field) in 2010 and 2011. Disease severity, Fusarium-damaged kernel (FDK) and mycotoxins were measured. Analysis of variance showed significant genotype and genotype by environment effect on all traits. Approximately $8 \%$ of the lines in field and $25 \%$ of the lines in greenhouse were more resistance than Tunisian108. A framework linkage map of 267 DArt plus 62 SSR markers was developed representing 239 unique loci and covering a total distance of $1887.6 \mathrm{cM}$. Composite interval mapping revealed nine QTL for FHB severity, four QTL for DON, and four QTL for FDK on seven chromosomes. Two novel QTL, $Q f h b . n d s u-3 B L$ and $Q f h b . n d s u-2 B$, were identified for disease severity, explaining 11 and $6 \%$ of the phenotypic variation, respectively. Also, a QTL with large effect on severity and a QTL with negative effect on FDK on chromosome $5 \mathrm{~A}$ were identified. Importantly, a novel region on chromosome $2 \mathrm{~B}$ was identified with multiple FHB resistance. Validation on these QTL would facilitate the durum wheat resistance breeding.

Keywords: durum wheat, FHB resistance, QTL, wheat scab, SSR

\section{Introduction}

Fusarium head blight (FHB), caused primarily by the fungus Fusarium graminearum Schwabe [teleomorph Gibberella zeae (Schw.) Petch], is a devastating disease of both common (T. aestivum L., $2 \mathrm{n}=6 \mathrm{x}=42$, AABBDD) and durum (T. turgidum L. var. durum Desf., $2 \mathrm{n}=4 \mathrm{x}=28$, AABB) wheat worldwide (Chen et al. 2007). Favorable conditions for Fusarium infection from 1997-2000 caused an epidemic in the US resulting in \$2.7

\footnotetext{
*Corresponding author; E-mail: Elias.Elias@ndsu.edu
} 
billion loss in wheat and barley (Hordeum vulgare L.) (Nganje et al. 2002), and \$6.2 billion in the Northern Great Plains from 1993 through 2001 (Nganje et al. 2004).

FHB is commonly referred to as "wheat scab"; a descriptive nomination that harkens back to the first documented FHB-outbreak, which occurred in England in 1884 (Stack 2003). FHB can cause bleached spikes, spikelet sterility, poor seed filling, low seed weight and tombstone seeds. Furthermore, grain marketing value is drastically affected by scabby wheat due to mycotoxin contamination from deoxynivalenol (DON), zearalenon (ZEN) and other masked toxins, and diminished milling and baking quality (Gilbert and Tekauz 2000). Development of host genetic resistance is the preferred strategy to reduce FHB effects, since cultural management practices and chemical controls are considered impractical or ineffective (Bai and Shaner 1994). Therefore, identification and incorporation of FHB resistance factors is an emphasis for plant breeders.

In recent years, notable high-quality common wheat cultivars with available FHB-resistance genes have been developed (Buerstmayr et al. 2012). However, introgression of FHB resistance sources from hexaploid wheat to tetraploid wheat has been nominal. The lack of resistance sources in tetraploid durum wheat has shifted efforts toward utilization of wild emmer (Oliver et al. 2005), alien species (Oliver et al. 2007) and exotic lines (Ghavami et al. 2011). North Dakota State University (NDSU) durum wheat breeding program screened approximately 7,500 durum wheat accessions and identified five lines with moderate levels of Type II resistance (Elias et al. 2005; Huhn et al. 2012). The five resistant lines (Tunisian 7, 18, 34, 36 and 108) are from the International Center for Agricultural Research in the Dry Areas (ICARDA), and are the only FHB-resistant durum lines identified to date. Ghavami et al. (2011) revealed that the genetic backgrounds of these five Tunisian lines are distinctly different from adapted cultivars. Huhn et al. (2012) reported that these five Tunisian lines could possess novel QTL for FHB resistance. Further, lines derived from these sources have shown resistance levels that can rival the best resistant hexaploid wheat (e.g., Sumai 3), with FHB severity of 10 to $25 \%$ (Ghavami et al. 2011). Objective of the current study was to identify genomic regions significantly associated with FHB resistance in an exotic Tunisian durum line 108.

\section{Materials and Methods}

\section{Development of backcross inbred line (BIL) population}

The present study used a BIL population developed from a cross of two durum wheat genotypes: 'Ben' and 'Tunisian 108' (Tun108). The recurrent parent 'Ben' is a medium height, high-yielding commercial spring durum wheat cultivar (Elias and Miller 1998) with $70-95 \%$ of infection to FHB according to our field and greenhouse results. The donor parent 'Tunisian 108' is an exotic Tunisian durum wheat genotype with moderate resistance to FHB. A total of $171 \mathrm{BC}_{1} \mathrm{~F}_{7}$ BILs along with their parental genotypes (' $\mathrm{Tu}$ nisian108' and 'Ben') and fourteen checks were evaluated for FHB resistance in this study. 


\section{Phenotypic evaluation}

Phenotypic evaluation was performed in two field trials and two greenhouse experiments during 2010 and 2011. The field trials were conducted in Prosper, North Dakota and the data for disease severity was recorded during both years. In the field, lines including the population and check plants were sown in randomized complete block design (RCBD) with two replicates. Plants were sown in 2-m row in May of both years. The field nursery was mist-irrigated and then inoculated using infected corn kernels (Stack 1989). The inoculum was a mixture of three different isolates of $F$. graminearum (R010, R1267, and $\mathrm{R} 1322$ ) to maximize the infection likelihood and to simulate natural environmental conditions. All genotypes reached anthesis almost similar time. The inoculation initiated at the beginning of heading stage and was repeated for two more times at 10 day intervals. In greenhouse experiments, each replication consisted of three plants in a $15 \mathrm{~cm}$ clay pot. The mixture of $F$. graminearum isolates (R010, R1267, and R1322) was applied. A $10 \mu \mathrm{l}$ droplet containing a mixture of conidia $(50,000 \mathrm{conidia} / \mathrm{ml})$ was used to inoculate four to six spikes per replication. Inoculum was injected directly into the second or third single spikelet near the bottom of the spike in anthesis stage, following procedure described by Stack (1989). Each inoculated spike was covered by misted plastic bag for 72 hours. Disease severity was scored as the percentage (0 to 100\%) of infected spikelets per spike 21 days after inoculation (Stack 1989). Disease severity was scored for 10 spikes as the decimal percentage ( 0 to $100 \%$ ) of visually infected spikelets per whole spikes 21 days after anthesis (Gosman et al. 2005). Deoxynivalenol (DON), 15-acetate deoxynivalenol (15ADON), Fusarium-damaged kernel (FDK) were measured in field experiment in 2011.

\section{Statistical analysis}

Analysis of variance for single and combined years for disease severity, FDK, DON, and 15ADON was conducted using Proc GLM of SAS version 9.1 (SAS Institute, Cary, NC). Prior to the combined analysis, error variances from the two locations were tested for homogeneity using a ratio of the two F values. Using Proc Corr command (SAS 9.1), Pearson's correlation between field and greenhouse experiments and seasons was conducted. Also, broad-sense heritability $\left(\mathrm{h}^{2}\right)$ was estimated.

\section{Genotypic analysis}

DNA from the 171 BIL population lines, nine checks, and two parental lines was extracted according to conditions prescribed by Triticarte Pty. Ltd. (http://www.triticarte. com.au/). All lines were genotyped using Diversity Array Technology (DArT) assay, performed by Triticarte Pty. Ltd. (Canberra, Australia; http://www.triticarte.com.au) (Akbari et al. 2006). An array of 2300 DArT markers, distributed across the entire durum wheat genome, was used to screen all the lines. In addition, 305 microsatellite markers were 
tested for polymorphism on the parental lines using standard polymerase chain reaction (PCR) conditions (Roeder et al. 1998).

\section{Genetic map construction and QTL analysis}

The genotypic marker data for all the polymorphic DArT and SSR on 171 BILs was used to construct the linkage maps using MAPMAKER v.2.0 (Lander et al. 1989). A set of DArT markers were selected and used as anchors based on available genetic maps (Mantovani et al. 2008; Peleg et al. 2008; Ghavami et al. 2011; Huang et al. 2012). The main criteria for anchor marker selection were that they have been mapped only to one specific chromosome in earlier studies (Mantovani et al. 2008; Peleg et al. 2008; Ghavami et al. 2011; Huang et al. 2012), and in total, cover as much of each chromosome as possible. A minimum LOD score of 3.0 and maximum distance of $30 \mathrm{cM}$ was used to assign markers to a particular group or chromosome. The remaining markers were then added to this initial map. Map distances were calculated from recombination fractions using the Kosambi mapping function (Kosambi 1944). Linkage maps were drafted using MapChart (Voorrips 2002). QTL analysis was carried out by composite interval mapping (CIM) using QTL Cartographer V2.5 (Wang et al. 2012). To detect authentic QTL, model 6 with forward and backward step-wise regression, five markers as cofactors to control genetic background, and a $10 \mathrm{cM}$ genome-wide scan window was used. A minimum LOD score of 2.0 was used for determining the presence of a putative QTL. Confidence intervals (CI) were obtained using positions \pm 1 LOD away from the peak and the QTL with overlapping CIs were considered as the same. Permutation test using 500 iterations also was performed to determine threshold LOD scores for each trait in each environment with 5\% error rate. QTL above threshold LOD scores were considered significant. Average phenotypic values for homogeneous environments (field and greenhouse) were separately utilized in QTL mapping.

\section{Results}

\section{Phenotypic analysis}

There were significant differences among genotypes including the parents for FHB disease severity when evaluated in the field and the greenhouse (Fig. S1*). Wide range of FHB infection rate were measured for control cultivars and lines. The highest disease severity were assessed for line D87450 and the lowest phenotypic values for disease severity were measured for Sumai 3 across the experiments (data not shown). Correlations were computed for years and disease severity. FHB severity values for field trials were significantly correlated across years $(\mathrm{r}=0.26, \mathrm{P}<0.0005)$. FHB severity values for greenhouse trials also were significantly correlated across years $(\mathrm{r}=0.16, \mathrm{P}<0.04)$. The only significant correlation between field and greenhouse environments resulted for 2011 $(\mathrm{r}=0.18, \mathrm{P}<0.01)$. Broad sense heritability was estimated for disease severity in field

\footnotetext{
*Further details about the Electronic Supplementary Material (ESM) can be found at the end of the article.
} 
experiments (23.15\%) and greenhouse screening (44.4\%). Generally, more lines showed high resistance in greenhouse than in field (Figure S1). Transgressive segregation for resistance to FHB severity was observed within the population (Figure S1). Fourteen lines in the field experiments and 43 lines in greenhouse screening performed significantly better than the resistant parent, while only 5 lines (TB-83, TB-87, TB-89, TB-50, TB120) showed high level of resistance across the experiments. These 5 lines showed only 10 to 20 percent of disease severity in greenhouse screening and 20 to 30 percent of disease incidence in the field across the experiments.

\section{Genetic map}

Seventy one out of 305 SSR markers detected polymorphism between the two parental genotypes 'Tunisian108' and 'Ben' and segregated in the population as expected. DArT genotyping identified an additional 310 polymorphic marker loci. Thus, totally 381 marker loci (71 SSRs and 310 DArTs) were used to genotype the mapping population. However, there were 30 highly distorted DArT markers, and thus being excluded. This left a total of 351 markers (71 SSRs and 280 DArTs) for map construction. Using a minimum LOD of 3 as critical value, nine SSRs and thirteen DArTs were further excluded. Therefore, a total of 329 marker loci (62 SSRs and 267 DArTs) were mapped to 239 unique positions located on 13 chromosomes (all except 4B were covered) at a minimum LOD of 3 (Figure S2). The number of marker loci mapped on individual chromosomes varied from 7 on $3 \mathrm{~A}$ to 66 on 3B. This map covered a total genetic distance of $1887.6 \mathrm{cM}$, with an average distance of $7.89 \mathrm{cM}$ between any two marker loci. The total genetic distance for B genome chromosomes was $1116.8 \mathrm{cM}$, and 770.8cM for A genome chromosomes. Individual chromosome lengths varied from $16.9 \mathrm{cM}$ for $3 \mathrm{~A}$ to $217.3 \mathrm{cM}$ for $5 \mathrm{~B}$. Comparative investigation indicated that 211 out of 329 (64.13\%) DArT and SSR mapped marker loci on the BIL population were consistent with recently available bread and durum wheat maps (Akbari et al. 2006; Crossa et al. 2007; Marone et al. 2012). Although DArT analysis revealed 11 polymorphic marker loci for chromosome 4B, they were excluded from mapping process due to unexpected distortion. Lack of polymorphic microsatellite loci for chromosome 4B was another reason this portion of the genome was not mapped. Due to same reasons, only a few DArT markers covered 3A chromosome.

\section{QTL mapping}

QTL analysis for FHB resistance in this population identified a total of nine regions significantly associated with FHB severity, four regions significantly associated with mycotoxin (DON and 15ADON), and four regions significantly associated with FDK (Table S1). These QTL were located on seven different chromosomes, including 1A, 1B, 2B, 3B, 5A, 5B, and 7B, with one QTL on chromosomes 1A (DON), two QTL on chromosome 5A (FHB severity in Greenhouse and FDK), two QTL on chromosome 1B (FDK and FHB severity in field), five QTL on chromosome 2B (FHB severity in greenhouse and field, 15ADON, DON and FDK), three QTL on chromosome 3B (FHB severity in 
greenhouse and field, and 15ADON), two QTL on chromosome 5B (FDK and FHB severity in greenhouse), and two QTL on chromosomes 7B (FHB severity in greenhouse and field). Fourteen out of seventeen QTL identified for FHB resistance mapped to a Bgenome chromosome. The QTL on chromosome 2B was present in both the 2010 greenhouse and 2011 field environment. The phenotypic variation controlled by these QTL ranged from $4.8 \%$ ( $Q f h b . n d s u-7 B)$ to $23.7 \%$ (Qfhb.ndsu-5A). The positive alleles for increased resistance at twelve loci, including the QTL on chromosome $2 \mathrm{~B}$ and $3 \mathrm{~B}$ and $Q f h b$. $n d s u-5 A$, were contributed by the moderately resistant Tunisian parent ('Tunisian 108'), while positive alleles for increased resistance at five loci (on chromosome 1A, 1B, 5A, 5B and 7B) were contributed by the susceptible parent 'Ben' with negative additive effects (Table S1). Further study revealed that the 5 most resistant lines were carrying all of the positive alleles introgressed from Tunisian 108.

\section{Discussion}

For several decades, new sources of resistance to FHB in bread wheat have contributed greatly to the breeding and cultivar development effort. The Tunisian germplasm utilized in this study presents an excellent resource for developing FHB-resistant durum cultivars. In this study, a number of lines were identified with medium to high level of FHB resistance. These lines provided resistance comparable with that shown in resistant hexaploid genotypes (e.g., 'Sumai 3' and 'Wangshubai'). Ghavami et al. (2011) observed transgressive segregation for FHB severity in a Tunisian-derived durum population; the same phenomenon was observed in the current investigation, where approximately $8 \%$ of lines (14 lines) in the field experiment and $25 \%$ of lines (43 lines) in the greenhouse screening showed lower levels of disease severity than the resistant parent. While only 5 lines were consistently resistant across the experiments.

Seventeen QTL were identified, however, only QTL on chromosomes 2B and 3B were consistently presented both in greenhouse and field over years, due to significant genotype by environment interaction (Table S1). Except for the QTL on chromosomes 1A, 2B and $3 \mathrm{~B}$, others have been identified previously in different durum wheat populations (Ruan et al. 2012). Interestingly, majority of the resistance QTL were located on B-genome. A QTL was identified on the long arm of chromosome $1 \mathrm{~B}$ using the combined field data. This QTL was not observed in either of the individual field year environments, despite the homogeneity of the 2010 and 2011 field data. The QTL was derived from the recurrent parent 'Ben', with $\mathrm{r}^{2}=16.3$. Several other researchers also have reported FHB resistance factors on chromosome 1B albeit at different locations (Shen et al. 2003; Liu et al. 2012). The novel QTL $Q f h b . n d s u-2 B$ showed significant effect for FHB resistance in field and greenhouse screening, with $\mathrm{r}^{2}$ of $6-10 \%$ for different traits. The $Q f h b . n d s u-2 B$ spans a $16.9 \mathrm{cM}$ marker interval. The marker ( $g w m 71)$ linked to this interval has been mapped to the short arm of chromosome 2B in various studies (Roeder et al. 1998; Marone et al. 2012). To date, a number of FHB QTL have been mapped to the short arm of chromosome 2B (Gervais et al. 2003; Somers et al. 2006) but they are not located in the same region as $Q f h b . n d s u-2 B$. Moreover, three QTL identified on the long arm of chro- 
mosome 3B were present in both the field and greenhouse experiments, and likely are the same. The chromosome 3B QTL identified here is apparently different from both Fhb1 in T. aestivum reported by Anderson et al. (2001), and Qfhs.ndsu-3BS on T. turgidum var. durum (Tun34) reported by Ghavami et al. (2011). To date, there are at least three reports (Bourdoncle and Ohm 2003; Paillard et al. 2004; Liu et al. 2007) for 3BL-FHB Type II resistance QTL with three associated microsatellite loci (Xgwm247, Xgwm131b and Xgwm285). None of these markers were polymorphic for Tunisian-derived population. The tightly associated microsatellite locus (Xbarc229) has been mapped on long arm of chromosome 3B (Roeder et al. 1998), which confirms the location of the 3B resistance FHB-QTL identified in this investigation.

A QTL with large effect $\left(r^{2}=24 \%\right)$ was identified on chromosome $5 \mathrm{~A}$, derived from 'Tunisian108', which might be at the same position shown in other findings in hexaploid wheat (Buerstmayr et al. 2003a,b; Gervais et al. 2003; Shen et al. 2003; Paillard et al. 2004). A QTL showing negative additive effect on FDK was also identified on chromosome 5A, which was derived from 'Ben'. Moreover, two QTLs were mapped on chromosome 7B. The markers associated with these loci were previously mapped on the proximal and the distal segments of the short arm of chromosome 7B (Mantovani et al. 2008, Marone et al. 2012). The resistance QTL located on the distal region of the short arm of chromosome 7B was derived from the recurrent parent 'Ben', and was previously identified in moderately resistant cultivars 'Dream' (Schmolke et al. 2005) and 'Cansas' (Klahr et al. 2007). The QTL located on the proximal region of the short arm of chromosome 7B has not been previously reported. Resistance alleles identified on chromosomes 1B, 5B and $7 \mathrm{~B}$ in this study are from the recurrent parent 'Ben' (non-donor parent), with differing levels of contribution to the phenotypic variation $(16.3 \%, 5.0 \%$, and $4.8 \%$, respectively). Resistance factors conferred by the recurrent (non-donor) parent are a widely reported phenomenon (Shen et al. 2003; Mardi et al. 2006; Ghavami et al. 2011). This occurrence is expected, considering the transgressive segregation observed for FHB resistance present in the population, the partial resistance and partial susceptibility of the population parents, and the general nature of FHB resistance as a quantitative trait. To date the 5 highly resistant lines in this experiment are recognized as promising lines in durum wheat project of NDSU, which can be used for further resistance breeding. Since these lines carrying positive alleles for all resistance QTL introgressed from resistant parent, the associated SSR markers in Table S1 can be used for marker assisted selection in further breeding program.

\section{Acknowledgements}

We thank the Wheat Germplasm Enhancement and the Durum Breeding project teams for their assistance, guidance and advice throughout this project. This material is based upon work supported by the U.S. Department of Agriculture, under Agreement No. 590206-9-063 to SFK. This is a cooperative project with the U.S. Wheat and Barley Scab Initiative. 


\section{References}

Akbari, M., Wenzl, P., Caig, V., Carlig, J., Xia, L., Yang, S., Uszynski, G., Mohler, V., Lehmensiek, A., Kuchel, H., Hayden M.J., Howes, N., Sharp, P., Vaughan, P., Rathmell, B., Huttner, E., Kilian, A. 2006. Diversity arrays technology (DArT) for high-throughput profiling of the hexaploid wheat genome. Theor. Appl. Genet. 113:1409-1420.

Anderson, J.A., Stack, R.W., Liu, S., Waldron, B.L., Fjeld, A.D., Coyne, C., Moreno-Sevilla, B.R., Mitchell, J., Song, Q.J., Cregan, P.B., Frohberg, R.C. 2001. DNA markers for a Fusarium head blight QTL in two wheat populations. Theor. Appl. Genet. 102:1164-1168.

Bai, G., Shaner, G. 1994. Scab of wheat: prospects for control. Plant Dis. 78:760-766.

Bourdoncle, W., Ohm, H.W. 2003. Quantitative trait loci for resistance to Fusarium head blight in recombinant inbred wheat lines from the cross Huapei 57-2/Patterson. Euphytica 131:131-136.

Buerstmayr, M., Huber, K., Heckmann, J., Steiner, B., Nelson, J.C., Buerstmayr, H. 2012. Mapping of QTL for Fusarium head blight resistance and morphological and developmental traits in three backcross populations derived from Triticum dicoccum $\times$ Triticum durum. Theor. Appl. Genet. 125:1751-1765.

Buerstmayr, H., Steiner, B., Hartl, L., Griesser, M., Angerer, N., Lengauer, D., Miedaner, T., Schneider, B., Lemmens, M. 2003a. Molecular mapping of QTLs for Fusarium head blight resistance in spring wheat. II. Resistance to fungal penetration and spread, Theor. Appl. Genet. 107:503-508.

Buerstmayr, H., Stierschneider, M., Steiner, B., Lemmens, M., Griesser, M., Nevo, E., Fahima, T. 2003 b. Variation for resistance to head blight caused by Fusarium graminearum in wild emmer (Triticum dicoccoides) originating from Israel. Euphytica. 130:17-23.

Chen, Y., Wang, J.X., Zhou, M.G., Chen, C.J., Yuan, S.K. 2007. Vegetative compatibility of Fusarium graminearum isolates and genetic study on their carbendazim resistance recombination in China. Phytopathol. 97:1584-1589.

Crossa, J., Burgueno, J., Dreisigacker, S., Vargas, M., Herrera-Foessel, S.A., Lillemo, M., Singh, R.P., Trethowan, R., Warburton, M., Franco, J., Reynolds, M., Crouch, J.H., Ortiz, R. 2007. Association analysis of historical bread wheat germplasm using additive genetic covariance of relatives and population structure. Genetics 177:1889-1913.

Elias, M.E., Manthey, F.A., Stack, R.W., Kianian, S.F. 2005. Breeding efforts to develop Fusarium head blight resistant durum wheat in North Dakota. In: Canty, S.M., Boring, T., Wardwell, J., Siler, L., Ward, R.W. (eds), Proceedings of the National Fusarium Head Blight Forum, 25-26. Michigan State University, 11-13, Dec, East Lansing, Milwaukee, WI.

Elias, E.M., Miller, J.D. 1998. Registration of 'Ben' durum wheat. Crop Sci. 38:895-896.

Gervais, L., Dedryver, F., Morlais, J.Y., Bodusseau, V., Negre, S., Bilous, M., Groos, C., Trottet, M. 2003. Mapping of quantitative trait loci for field resistance to Fusarium head blight in an European winter wheat. Theor. Appl. Genet. 106:961-970.

Ghavami, F., Elias, E.M., Mamidi, S., Ansari, O., Sargolzaei, M., Adhikari, T., Mergoum, M., Kianian, S.M. 2011. Mixed model association mapping for Fusarium head blight resistance in Tunisian-derived durum wheat populations. Gen. Genom. Genet. 1:209-218.

Gilbert, J., Tekauz, A. 2000. Review: Recent developments in research on Fusarium head blight of wheat in Canada. Can. J. Plant Pathol. 22:1-8.

Gosman, N., Chandler, E., Thomsett, M., Draeger, R., Nicholson, P. 2005. Analysis of the relationship between parameters of resistance to Fusarium head blight and in vitro tolerance to deoxynivalenol of the winter wheat cultivar WEK0609 (R). Eur. .J Plant Pathol. 111:57-66.

Huang, B.E., George, A.W., Forrest, K.L., Kilian, A., Hayden, M.J., Morell, M.K., Cavanagh, C.R. 2012. A multiparent advanced generation inter-cross population for genetic analysis in wheat. Plant Biotech. J. 10:826-839.

Huhn, M., Elias, E., Ghavami, F., Kianian, S., Chao, S., Zhong, S., Alamri, M., Yahyaoui, A., Mergoum, M. 2012. Tetraploid Tunisian wheat germplasm as a new source of Fusarium head blight resistance. Crop Sci. 52:136-145. 
Klahr, A., Zimmermann, G., Wenzel, G., Mohler, V. 2007. Effects of environment, disease progress, plant height and heading date on the detection of QTLs for resistance to Fusarium head blight in an European winter wheat cross. Euphytica 154:17-28.

Kosambi, D. D. 1944. The estimation of map distances from recombination values. Ann. Eugen. 12:172-175.

Lander, E.S., Botstein, D. 1989. Mapping Mendelian factors underlying quantitative traits using RFLP linkage maps. Genetics. 121:185-199.

Liu, S., Abate, Z.A., Lu, H., Musket, T., Davis, G.L., McKendry, A.L. 2007. QTL associated with Fusarium head blight resistance in the soft red winter wheat Ernie. Theor. Appl. Genet. 115:417-427.

Liu, S., Christopher, M.D., Griffey, C.A., Hall, M.D., Gundrum, P.G., Brooks, W.S. 2012. Molecular characterization of resistance to Fusarium head blight in U.S. soft red winter wheat breeding line VA00W-38. Crop Sci. 52:2283-2292.

Mantovani, P., Maccaferri, M., Sanguineti, M.C., Tuberosa, R., Catione, I., Wenzl, P., Thomson, B., Carling, J., Huttner, E., De Ambrogio, E., Kilian, A. 2008. An integrated DArT-SSR linkage map of durum wheat. Mol. Breed. 22:629-648.

Mardi, M., Pazouki, L., Delavar, H., Kazemi, M.B., Ghareyazie, B., Steiner, B., Nolz, R., Lemmens, M., Buerstmayr, H. 2006. QTL analysis of resistance to Fusarium head blight in wheat using a Frontana-derived population. Plant Breed. 125:313-317.

Marone, D., Laido, G., Gadaleta, A., Colasuonno, P., Ficco, D.B.M., Giancaspro, A., Giove, S., Panio, G., Russo, M.A., De Vita, P., Cattivelli, L., Papa, R., Blanco, A., Mastrangelo, A.M. 2012. A high-density consensus map of A and B wheat genomes. Theor. Appl. Genet. 125:1619-1638.

Nganje, W.E., Kaitibie, S., Wilson, W.W., Leistritz., F.L., Bangsund, D.A. 2004. Economic impacts of Fusarium head blight in wheat and barley: 1993-2000, Agribusiness and Applied Economics Rep. No. 538, North Dakota State Univ, Fargo.

Nganje, W.E., Bangsund, D.A., Leistnitz, F.L., Wilson, W.W., Tiapo, N.M. 2002. Estimating the economic impact of a crop disease: the case of Fusarium head blight in U.S. wheat and barley. In: Canty, S.M., Lewis, J., Siler, L., R.W. Ward, R.W. (eds), Proceedings of the National Fusarium Head Blight Forum, 275-281. Erlanger, KY, 7-9 Dec, Michigan State University.

Oliver, R.E., Stack, R.W., Miller, J.D., Cai, X. 2007. Reaction of wild emmer wheat accessions to Fusarium head blight. Crop Sci. 47:893-899.

Oliver, R.E., Cai, X., Xu, S.S., Chen, X., Stack, R.W. 2005. Wheat alien species derivatives: A novel source of resistance to Fusarium head blight in wheat. Crop Sci. 45:1353-1360.

Paillard, S., Schnurbusch, T., Tiwari, R., Messmer, M., Winzeler, M., Keller, B., Schachermayr, G. 2004. QTL analysis of resistance to Fusarium head blight in Swiss winter wheat (Triticum aestivum L.). Theor. Appl. Genet. 109:323-332.

Peleg, Z., Saranga, Y., Suprunova, T., Ronin, Y., Roder, M.S., Kilian, A., Korol, A.B., Fahima, T. 2008. Highdensity genetic map of durum wheat $\times$ wild emmer wheat based on SSR and DArT markers. Theor. Appl. Genet. 117:103-115.

Roeder, M.S., Korzun, V., Wendehake, K., Plaschke, J., Tixier, M.H., Leroy, P., Ganal, M.W. 1998. A microsatellite map of wheat. Genetics. 149:2007-2023.

Ruan, Y.F., Comeau, A., Langevin, F., Hucl, P., Clarke, J.M., Brule-Babel, A., Pozniak, C.J. 2012. Identification of novel QTL for resistance to Fusarium head blight in a tetraploid wheat population. Genome. 55:853-864.

Schmolke, M., Zimmermann, G., Buerstmayr, H., Schweizer, G., Miedaner, T., Korzun, V., Ebmeyer, E., Hartl, L. 2005. Molecular mapping of Fusarium head blight resistance in the winter wheat population Dream/ Lynx. Theor. Appl. Genet. 111:747-756.

Shen, X., Ittu, M., Ohm, H. 2003. Quantitative trait loci conditioning resistance to Fusarium head blight in wheat line F201R. Crop Sci. 43:850-857.

Somers, D.J., Fedak, G., Clarke, J., Cao, W. 2006. Mapping of FHB resistance QTLs in tetraploid wheat. Genome. 49:1586-1593.

Stack, R.W. 2003. History of Fusarium head blight with emphasis on North America, In: Leonard, K.J., Bushnell, W.R. (eds), Fusarium head blight of wheat and barley, pp. 1-34. APSPress, St. Paul, MN.

Stack, R.W. 1989. A comparison of the inoculum potential of ascospores and conidia of Gibberella zeae. Can. J. Plant Pathol. 11:137-142. 
Triticarte Pty. Ltd. Triticarte whole-genome genotyping service for wheat and barley. Available at: http://www. triticarte.com.au/.

Voorrips, R.E. 2002. MapChart: Software for graphical presentation of linkage maps and QTLs. J Hered. 93:77-78.

Wang, S., Basten, C.J., Zeng, Z.B. 2012. Windows QTL Cartographer 2.5. Department of Statistics, North Carolina State University, Raleigh, NC. (http://statgen.ncsu.edu/qtlcart/WQTLCart.htm).

\section{Electronic Supplementary Material (ESM)}

Electronic Supplementary Material (ESM) associated with this article can be found at the website of CRC at https://akademiai.com/loi/0806

Electronic Supplementary Table S1. Putative QTL for FHB severity, FDK and toxic components detected in Tunasian 108/Ben//Ben $\mathrm{BC}_{1} \mathrm{~F}_{7}$ BIL mapping population

Electronic Supplementary Table S2. Disease severity and toxin levels in Tunisian108/Ben//Ben $\mathrm{BC}_{1} \mathrm{~F}_{7}$ population across the experiments

Electronic Supplementary Figure S1. Frequency distribution of FHB severity for Tunisian108/Ben/Ben population in two greenhouse (point inoculation) and two field experiments (spawn inoculation) in 2010 and 2011. The average of FHB infection for the parents and the resistant (Sumai3) and susceptible (D87450) checks are indicated by arrows

Electronic Supplementary Figure S2. Genetic linkage map of 329 mapped markers and putative QTL for Tunisian 108/Ben//Ben $\mathrm{BC}_{1} \mathrm{~F}_{7}$ population; $\mathrm{GH}$ presents $\mathrm{FHB}$ severity in greenhouse, $\mathrm{F}$ represents $\mathrm{FHB}$ severity in field, DON represents deoxynivalenol, 15ADON represents 15-acetate deoxynivalenol, and FDK represents Fusarium-damaged kernel 